University of Nebraska - Lincoln

DigitalCommons@University of Nebraska - Lincoln

Faculty Publications, Department of Physics and Astronomy

Research Papers in Physics and Astronomy

$1-1-2006$

\title{
The electronic structure and band hybridization of Co/Ti doped $\mathrm{BaFe}_{12} \mathrm{O}_{19}$
}

\author{
Natalie Palina \\ Physikalisches Institut der Universität Bonn, palina@physik.uni-bonn.de \\ H. Modrow \\ Physikalisches Institut der Universität Bonn, Bonn, Germany \\ R. Müller \\ Institut für Physikalische Hochtechnologie, Jena, Germany \\ J. Hormes \\ Louisiana State University \\ Peter A. Dowben \\ University of Nebraska-Lincoln, pdowben@unl.edu \\ See next page for additional authors
}

Follow this and additional works at: https://digitalcommons.unl.edu/physicsfacpub

Part of the Physics Commons

Palina, Natalie; Modrow, H.; Müller, R.; Hormes, J.; Dowben, Peter A.; and Losovyj, Yaroslav B., "The electronic structure and band hybridization of $\mathrm{Co} / \mathrm{Ti}$ doped $\mathrm{BaFe}_{12} \mathrm{O}_{19}$ " (2006). Faculty Publications, Department of Physics and Astronomy. 44.

https://digitalcommons.unl.edu/physicsfacpub/44

This Article is brought to you for free and open access by the Research Papers in Physics and Astronomy at DigitalCommons@University of Nebraska - Lincoln. It has been accepted for inclusion in Faculty Publications, Department of Physics and Astronomy by an authorized administrator of DigitalCommons@University of Nebraska Lincoln. 


\section{Authors}

Natalie Palina, H. Modrow, R. Müller, J. Hormes, Peter A. Dowben, and Yaroslav B. Losovyj 


\title{
The electronic structure and band hybridization of $\mathrm{Co} / \mathrm{Ti}$ doped $\mathrm{BaFe}_{12} \mathrm{O}_{19}$
}

\author{
Natalie Palina*, H. Modrow*, R. Müller ${ }^{\dagger}$, J. Hormes $\$$, P. A. Dowben ${ }^{\S}$, and Ya. B. Losovyj $\$ \S$ \\ * Physikalisches Institut der Universität Bonn, Bonn, Germany \\ $\dagger$ Institut für Physikalische Hochtechnologie, Jena, Germany \\ $¥$ Center for Advanced Microstructures and Devices, Louisiana State University, \\ Baton Rouge, Louisiana, USA \\ $\S$ Department of Physics and Astronomy and the Center for Material Research \\ and Analysis, University of Nebraska-Lincoln, Lincoln, Nebraska, USA \\ Submitted May 2005; accepted 10 August 2005; \\ available online 1 September 2005; published in print January 2006.
}

\begin{abstract}
We identify contributions to the valence band of the nanosized $\mathrm{BaFe}_{12-2 x} \mathrm{Co}_{x} \mathrm{Ti}_{x} \mathrm{O}_{19}$ barium ferrite particles, from the cobalt and titanium dopants. Resonant photoemission results show that cobalt and titanium dopants strongly hybridize with the barium ferrite matrix. Fano resonances are identified in the valence band region, at the $\mathrm{Ba}(5 \mathrm{~s}), \mathrm{Ti}(3 \mathrm{p})$ and $\mathrm{Co}(3 \mathrm{p})$ thresholds, and there are significant contributions to the density of states, residing within $2 \mathrm{eV}$ of the Fermi level, from barium and/or iron.
\end{abstract}

Keywords: Doping ferrites, Phase equilibria of ferrites

\section{Introduction}

There has been a significant thrust to develop nanocrystallites of magnetite $\left(\mathrm{Fe}_{3} \mathrm{O}_{4}\right)$ and other ferrites [1], [2], [3] and [4] on the multigram scale for application as ferrofluids [5] and [6] and magnetic recording media. The magnetic anisotropy of the $\mathrm{BaFe}_{12-2 x} \mathrm{Co}_{x} \mathrm{Ti}_{x} \mathrm{O}_{19}$ barium ferrite particles strongly depends on the extent of cobalt and titanium doping [6], so that the bonding and hybridization of the dopants with the barium ferrite matrix is of some interest.

Superlattices, notably of oxides, with unusual electronic and magnetic properties as well as charge transfer in complex oxides have been investigated by photoemission and resonant photoemission [7], [8], [9], [10], [11], [12], [13] and [14]. While ultraviolet photoemission suffers from the drawback that the technique is an extremely surface sensitive technique, resonant photoemission can be exploited to some effectiveness to ascertain charge localization [7] and [8] and provide some insight as to bonding configuration [11], [12], [13], [14] and [15]. We have undertaken to use photoemission, with some theoretical support, to explore the local environment of the doping species $(\mathrm{Co} / \mathrm{Ti})$ within nanosized $\mathrm{BaFe}_{12} \mathrm{O}_{19}$ particles.

\section{Experimental and theoretical methodology}

The nanocrystalline barium ferrite $\mathrm{BaFe}_{12-2 x} \mathrm{Co}_{x} \mathrm{Ti}_{x} \mathrm{O}_{19}$ particles were prepared by the glass crystallization method, as described elsewhere [3]. A compressed pellet was prepared suitable for ultra-high vacuum photoemission. The samples were prepared by a sequence of sputtering an annealing to remove contamination from the large surface area of these samples $\left(120 \mathrm{~m}^{2} / \mathrm{g}\right)$, but care was taken to prevent sintering and excessive preferential segregation, as determined from the shallow Ba 5p, Ti 3p, Co 3p and Fe 3p core levels. The average particle size of the $\mathrm{BaFe}_{12-2 x} \mathrm{Co}_{x} \mathrm{Ti}_{x} \mathrm{O}_{19}$ particles was $9 \mathrm{~nm}$ in diameter, with a saturation magnetization of $22.8 \mathrm{Am}^{2} / \mathrm{kg}$ and coercive field of $1.1 \mathrm{kA} / \mathrm{m}$.

The angle-resolved photoemission spectra were obtained from the polarized synchrotron radiation dispersed by a 3 $\mathrm{m}$ toroidal grating monochromator, at the Center for Microstructures and Devices (CAMD) in combination with hemispherical electron energy analyzer with photoelectrons collected normal to the surface, as described elsewhere [16]. The combined resolution of the electron energy analyzer and monochromator, for the spectra shown herein, is 120 $150 \mathrm{meV}$ for high kinetic photon energies $(50-120 \mathrm{eV})$, 
but there is higher resolution at the lower photon energies (about $80 \mathrm{meV}$ for photon energies of 25-40 eV). With the highly plane polarized synchrotron light, photoemission experiments were undertaken with a light incidence angle of $45^{\circ}$ with respect to the surface normal ( $\mathrm{s}+\mathrm{p}$ polarization) and with the photoelectrons collected along surface normal. All binding energies are referenced to the Fermi level, as determined from clean tantalum in contact with the sample.

To model the various contributions to the photoemission, we undertook theoretical calculations of the density of states using the FEFF8 code [17], whose suitability to obtain detailed information on the electronic structure has been shown in a number of previous studies, e.g. [18], [19] and [20]. This self-consistent approach (FEFF8) are real space Green's function (RSGF) calculations, which include full multiple scattering (FMS) from atoms within a cluster of a given size, using the spinor relativistic approximation for the solutions of the Dirac equation. Naturally, a cluster approach limits the resolution of the density of states calculations. This limitation is evident in Fig. 1b, as the density
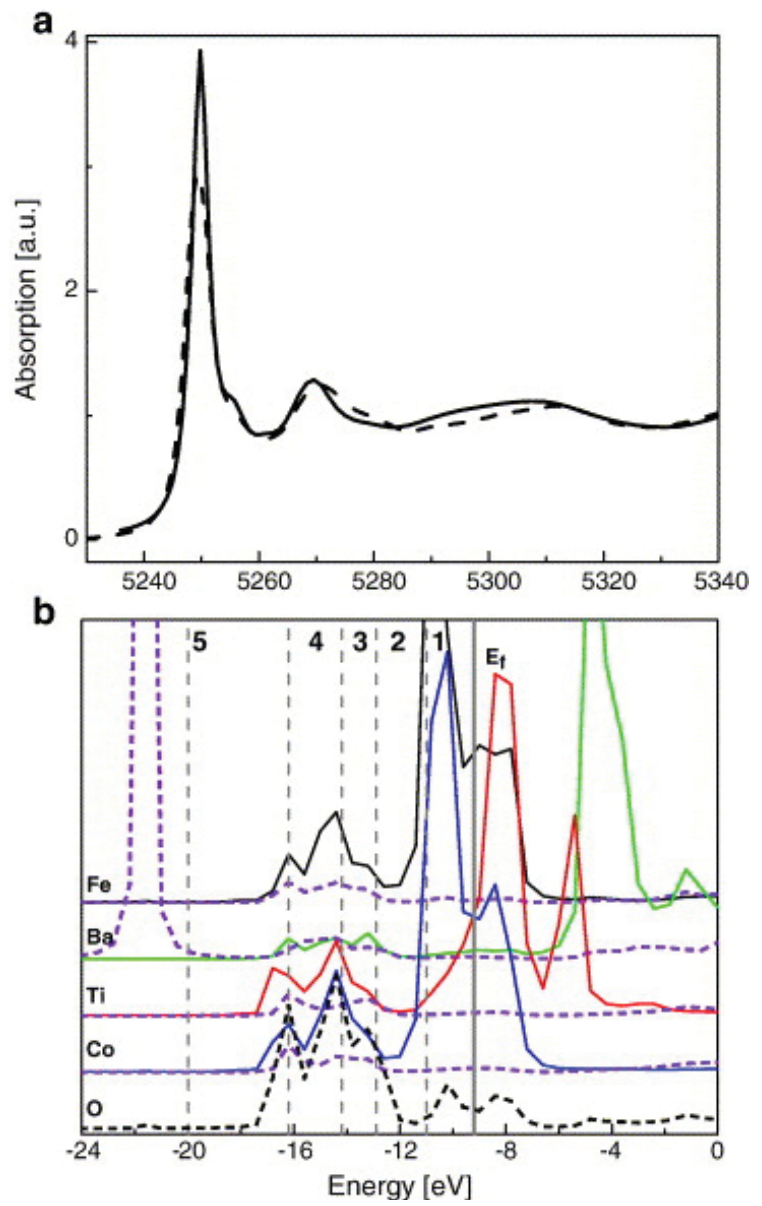

Fig. 1. (A) $B a L_{I I I}-X A N E S$ spectra of experimental (dashed) and calculated using FEFF 8 code (solid) $\mathrm{BaFe}_{12} \mathrm{O}_{19}$, (B) The partial $p$ - (dashed line) and $d$ - (solid line) projected density of states for (doped) bariumhexaferrite as obtained by the FEFF 8 code. The position of the vertical lines labeled 1-5 corresponds to the valence band photoemission features displayed in Fig. 2, plotted relative to the Fermi energy as estimated by FEFF8. of states calculation does not reproduce the band-gap of the material correctly, which just appears as a dip in the density of states plot. Nonetheless, these model calculations determine the position of the various bands sufficiently well to aid in the assignment of the photoemission features. These calculations take in account the photoemission final-state somewhat better than is the case in ground state calculations as the Fermi energy position is estimated in the presence of a screened core hole.

The good agreement between calculated and experimental barium $\mathrm{L}_{\mathrm{III}}$-XANES spectra, as shown in Fig. 1a, is a "validation" of the efficacy of these calculations. XANES spectra were collected at the XMP (X-Ray Microprobe) beamline at the Center for Microstructures and Devices (CAMD). For the XANES spectra, monochromatic light was obtained by using a double crystal monochromator of Lemonnier type [21], equipped with $\operatorname{Si}(311)$ crystal pair $(d=3.276 \AA)$ and the overall resolution was $0.8-1.0 \mathrm{eV}$.

\section{Resonant photoemission}

In the valence band region, there are several occupied bands that are readily distinguished at 1.8, 3.2, 4.8, 7 and $10.8 \mathrm{eV}$, as seen in Fig. 2. More careful analysis suggests that the feature at $7 \mathrm{eV}$ is in fact a result of contributions from two broad photoemission features at about 6.3 and 7.6

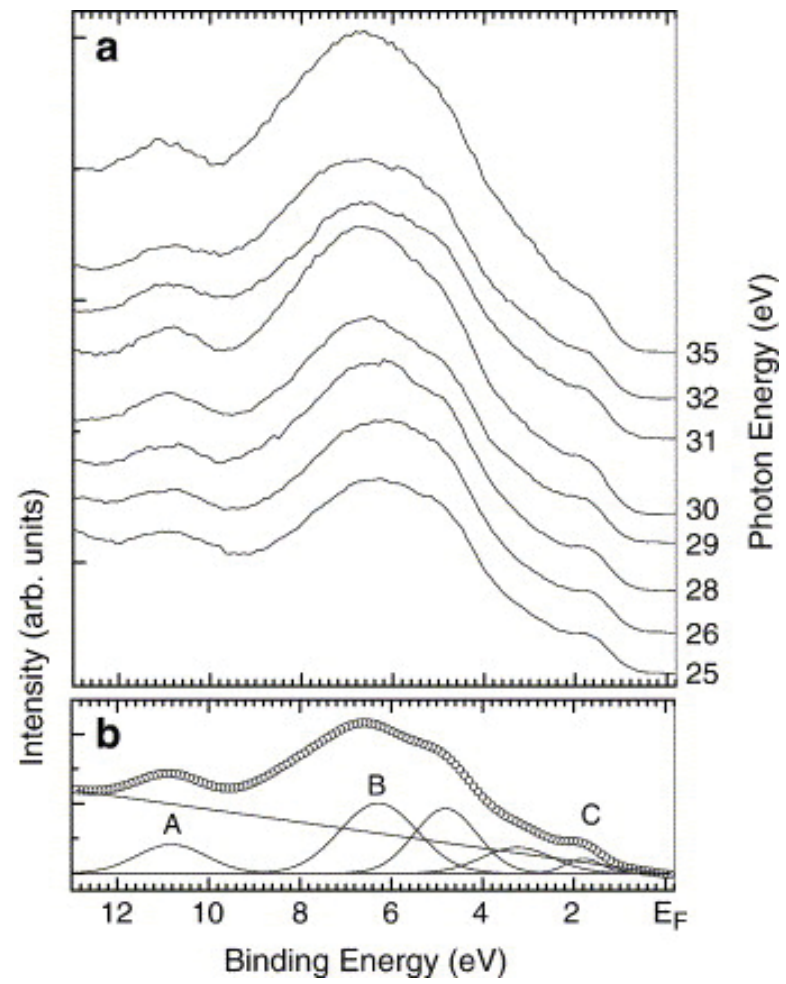

Fig. 2. Valence band photoemission spectra of nanocrystalline barium ferrite $\mathrm{BaFe}_{12-2 x} \mathrm{Co}_{x} \mathrm{Ti}_{x} \mathrm{O}_{19}$ particles as a function of photon energy across the barium $5 \mathrm{~s}$ core level threshold. The spectra were collected along normal to the surface at room temperature. (b) The various contributions to the spectra are indicated by the deconvolution of the spectra taken at $29 \mathrm{eV}$ photon energy. 
$\mathrm{eV}$ binding energy, thus explaining the weak shoulder, at higher binding energies, of the main photoemission feature, as indicated in Fig. 2.

As seen in Fig. 3 and Fig. 4 , the barium $5 p_{1 / 2}$ and $5 p_{3 / 2}$ shallow core levels are observed at 17.5 and $15.6 \mathrm{eV}$, respectively, are shifted from the expected $17.2 \mathrm{eV}$ and 14.9 $\mathrm{eV}$ binding energies [22], as is expected from strong oxida-

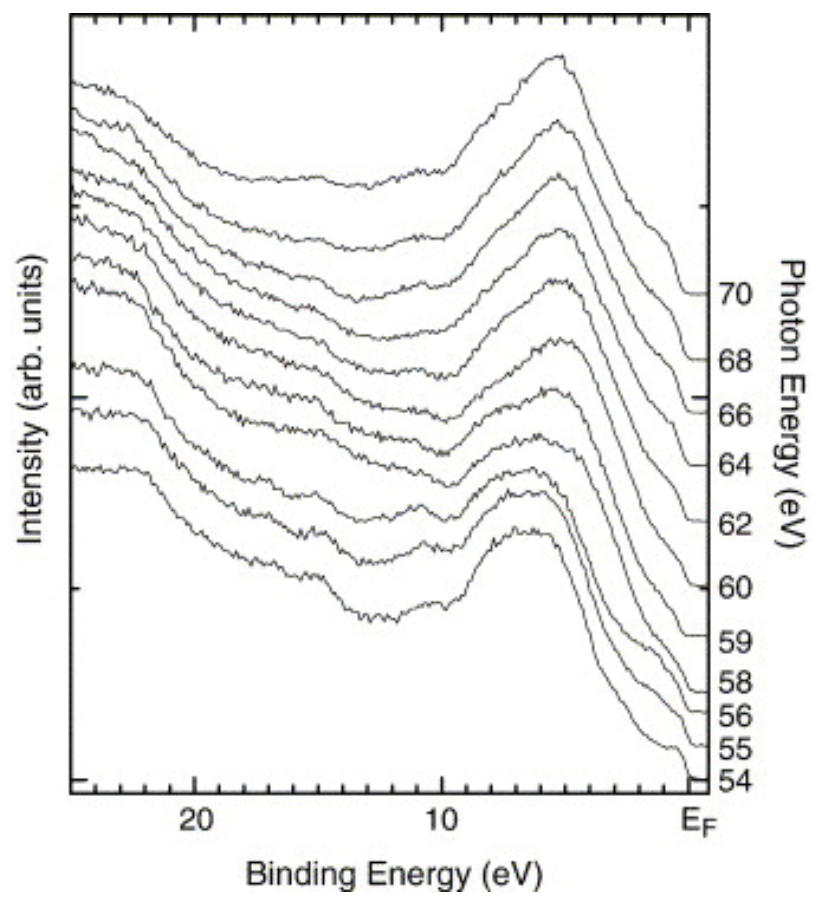

Fig. 3. Valence band photoemission spectra of nanocrystalline barium ferrite $\mathrm{BaFe}_{12-2 x} \mathrm{Co}_{x} \mathrm{Ti}_{x} \mathrm{O}_{19}$ particles as a function of photon energy across the titanium $3 \mathrm{~s}$ and cobalt $3 \mathrm{p}$ core level thresholds. The spectra were taken at room temperature, with the photoelectrons collected along normal to the surface.
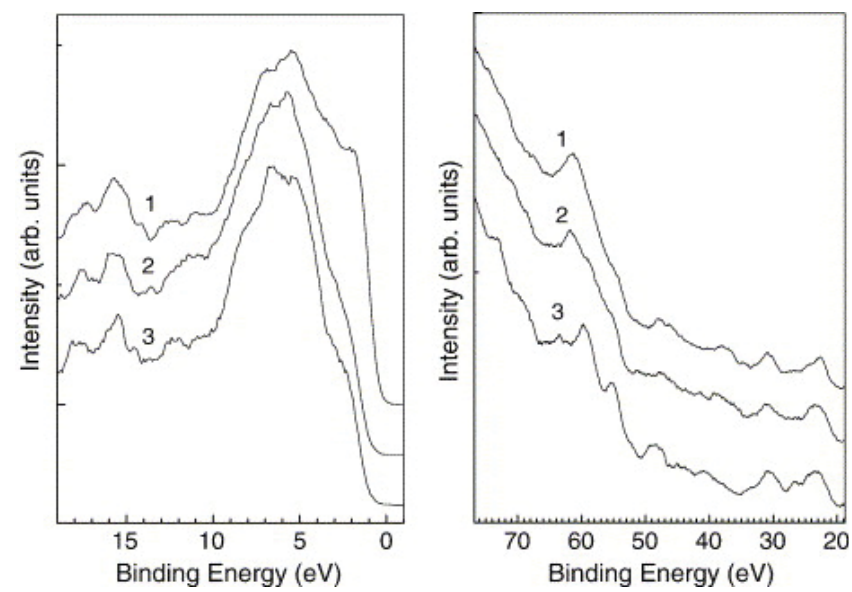

Fig. 4. Photoemission spectra taken at room temperature after prolonged heating followed after several short heating/sputtering cycles: (1) prolonged heating, $10 \mathrm{~h}$ annealing at $685 \mathrm{~K}$, (2) after brief heating, (3) after sputtering. Spectra of the Co $3 p$ and Fe $3 p$ shallow cores (right panel), showing enhancement of Co $3 p$ and/or Co and Ba Auger with annealing while the enhancement of the valence band $1.8 \mathrm{eV}$ binding energy feature is shown at left. The photon energy was $115 \mathrm{eV}$. tion and charge transfer. Similar increases in binding energies are observed with the other shallow core levels, again characteristic of the oxide. Thus the resonant photoemission threshold photon energies could be as much as 0.5 to $1 \mathrm{eV}$ greater than the 'nominal' binding energy.

In spite of the limitations of photoemission, synchrotron based resonant photoemission provided evidence of pronounced resonances in the valence band spectra of a compress of $\mathrm{Co} / \mathrm{Ti}$ doped nanosized $\mathrm{BaFe}_{12} \mathrm{O}_{19}$ particles. The valence band resonances occur at photon energy characteristics of the $\mathrm{Ba} 5 \mathrm{~s}$ and Ti $3 \mathrm{p}$ core to bound excitation energies, at 30.3 and $32.6 \mathrm{eV}$ photon energies respectively, as seen in Fig. 1. In the region of $30 \mathrm{eV}$ photon energy, these resonant enhancements are most pronounced in the valence band features at 1.8, 7 and $10.8 \mathrm{eV}$ binding energy, while the feature at $4.8 \mathrm{eV}$ binding energy undergoes a 'delayed' resonance at $32 \mathrm{eV}$ photon energy.

The valence band resonances at $\mathrm{Ba} 5 \mathrm{~s}$ threshold, obtained in the vicinity of $30 \mathrm{eV}$ photon energy are summa-

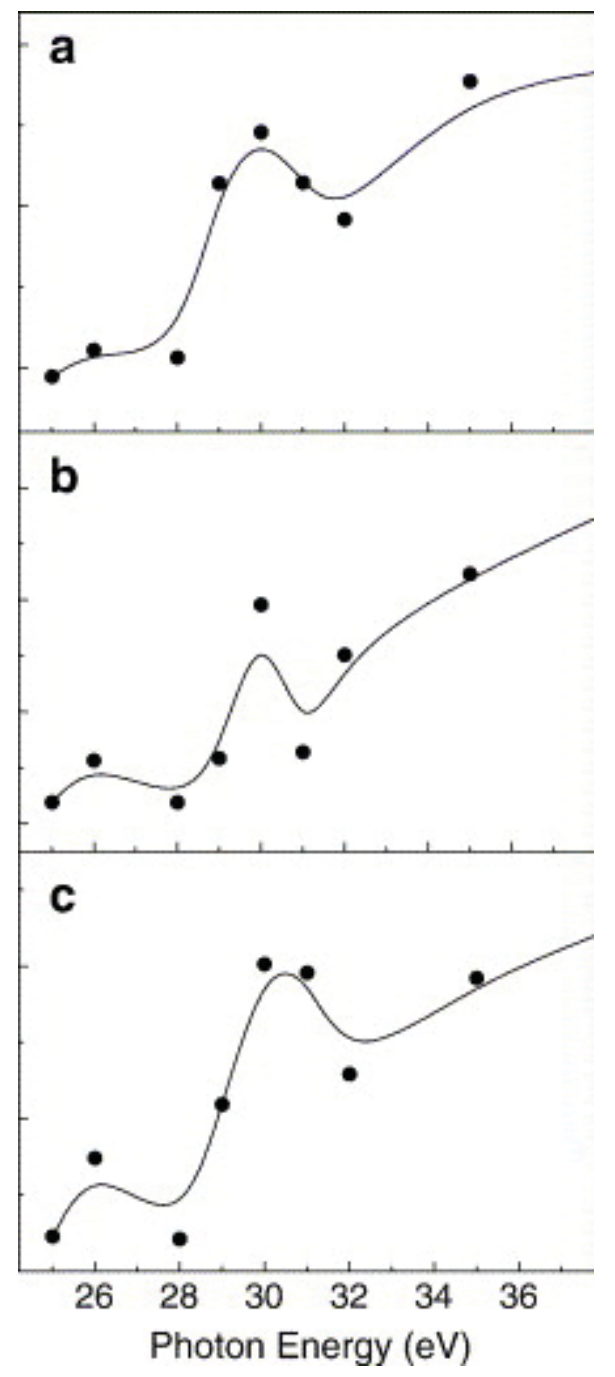

Fig. 5. The intensities of the photoemission features at $10.8 \mathrm{eV}$ (a), 7.7 $\mathrm{eV}$ (b) and $1.8 \mathrm{eV}$ (c) binding energy for nanocrystalline barium ferrite $\mathrm{BaFe}_{12-2 x} \mathrm{Co}_{x} \mathrm{Ti}_{x} \mathrm{O}_{19}$ particles, as a function of photon energy. 
rized in Fig. 5. The intensities, with changes in photon energy, exhibit the characteristic Fano resonance line shape, but this can occur in photoemission of the transition metals without invoking a super-Koster Kronig type resonance photoemission [23].

Additional enhancements of the valence band features at about 1.8 and $7 \mathrm{eV}$ binding energy occurs at about $53 \mathrm{eV}$ photon energy while a strong enhancement of the band at $4.8 \mathrm{eV}$ occurs at about 62 to $66 \mathrm{eV}$ photon energy, as indicated in Fig. 3.

\section{Atomic contributions to the valence band features}

Because of the strong resonant behavior, we can make some assignments of elemental contribution to the various bands observed in the occupied valence band structure of cobalt and titanium doped $\mathrm{BaFe}_{12-2 x} \mathrm{Co}_{x} \mathrm{Ti}_{x} \mathrm{O}_{19}$ nanocrystallites. The valence band feature at $1.8 \mathrm{eV}$ must contain both barium and transition metal iron and cobalt contributions as this feature is resonantly enhanced by excitations from the $\mathrm{Ba} 5 \mathrm{~s}$ core (nominally at $30.3 \mathrm{eV}$, for unoxidized $\mathrm{Ba}$ ) as well as at $60-62 \mathrm{eV}$, by excitations from the Co $3 \mathrm{p}_{1 / 2}$ and $3 p_{3 / 2}$ cores (nominally at $58.9 \mathrm{eV}$, for unoxidized $\mathrm{Co}$ ). This is consistent with our model calculations, which suggest presence of $\mathrm{Ba} 5 \mathrm{~d}$ and oxygen $2 \mathrm{p}$ contributions with strong $\mathrm{Fe}$ and Co contributions, but much smaller Ti contributions to the density of states close to the Fermi level (Fig. $\mathbf{1 b}$, vertical line labeled 1).

The strong feature at about $4.8 \mathrm{eV}$ binding energy does not strongly resonate across the Ba shallow core levels but does undergo a photoemission enhancement at photon energies in the range of $62-66 \mathrm{eV}$. This tends to indicated that this band has both cobalt and titanium contributions. The broad range of photon energies, where photoemission enhancement occurs, tends to suggest that there are multiple resonances contributing to the valence band photoemission, and titanium $3 \mathrm{~s}$ (nominally at $58.7 \mathrm{eV}$, for unoxidized Ti) and cobalt $3 \mathrm{p}$ (nominally at $58.9 \mathrm{eV}$, for unoxidized $\mathrm{Co}$ ) lie very close in binding energy. As the core level shifts, due to oxidation which tends to separate the core level binding energies, this will tend to broaden the width of the photoemission resonance, as is observed in the vicinity of $62 \mathrm{eV}$ photon energy. The "delayed" photoemission resonance of this feature at $4.8 \mathrm{eV}$ binding energy at $32 \mathrm{eV}$, instead of $30 \mathrm{eV}$ photon energy is consistent with the assignment of some titanium weight to this band (the Ti $3 p$ shallow core occurs at nominally at $32.6 \mathrm{eV}$, for unoxidized Ti). Here theory suggests that the density of states in this region of the valence band is principally due to Ti $3 \mathrm{~d}$ and Co $3 \mathrm{~d}$ (Fig. 1b, vertical line labeled 3).

The features at about 7 and $10.8 \mathrm{eV}$ binding energy show resonant enhancements in the valence band spectra at 30 $\mathrm{eV}$ photon energy as do the barium shallow $5 \mathrm{p}$ cores, and must therefore contain barium contributions. As the feature at $7 \mathrm{eV}$ binding energy also undergoes a resonant enhance- ment at $53 \mathrm{eV}$ photon energy, by excitations from the $\mathrm{Fe}$ $3 p_{1 / 2}$ and $3 p_{3 / 2}$ cores (nominally at $52.7 \mathrm{eV}$, for unoxidized $\mathrm{Fe}$ ), we believe this feature also contains some iron contributions. On this basis, we must conclude that barium is strongly hybridized to iron mediated by the oxygen as both the bands at 1.8 and $7 \mathrm{eV}$ binding energy contain both barium and iron contributions. Strong Fe 3d and Co contributions in this region are found in the calculated density of states (Fig. 1b, vertical line labeled 4) but little barium. If this calculated density calculation is indeed representative, then the only possible explanation of the photoemission enhancement at a barium core edge would be that the barium must be in close proximity to iron to permit extra-atomic resonant enhancements. Such extra-atomic excitation, although generally a weaker contributions to the resonant photoemission process than intra-atomic excitations, would explain the greater than expected $\mathrm{Fe} 4 \mathrm{p}$ contributions to the $1.8 \mathrm{eV}$ photoemission feature and the stronger than expected barium contributions to the photoemission features at 7 and $10.8 \mathrm{eV}$ binding energy.

Choosing a photon energy above both the Ba $4 \mathrm{~d}$ thresholds (nominally at $92.6 \mathrm{eV}$ and $89.9 \mathrm{eV}$, for unoxidized $\mathrm{Ba}$ ) and the Fe 3s threshold (nominally at $91.3 \mathrm{eV}$, for unoxidized $\mathrm{Fe}$ ), we can enhance the iron and barium contributions to the valence band photoemission spectra, as seen in the spectra taken at a photon energy of $115 \mathrm{eV}$. This is evident from a comparison of the spectra in Fig. $4(115 \mathrm{eV}$ incident photon energy) with Fig. 3 (54 to $70 \mathrm{eV}$ photon energies). The feature at $1.8 \mathrm{eV}$ is strongly enhanced, and the resonances at the barium and cobalt core threshold suggest that barium may also be strongly hybridized with cobalt.

Both cobalt and titanium contribute to the band at 4.8 $\mathrm{eV}$ binding energy and although both are dopants. Uniform placements of cobalt and titanium dopants throughout each crystallite, therefore seems unlikely. Surface/interface segregation of cobalt and titanium is consistent with the annealing studies discussed below (vide infra). While inhomogeneous $\mathrm{Co} / \mathrm{Ti}$ concentrations in different particles cannot be excluded on the basis of the data presented here, this alone cannot explain these results nor the segregation results discussed below. If cobalt is in close proximity to titanium, then, as with iron and barium, extra-atomic resonant enhancement of largely Ti $3 \mathrm{~d}$ bands (at $4.8 \mathrm{eV}$ binding energy) can occur at the cobalt edge, as suggested by the calculated partial density of states (Fig. 1b, the vertical line labeled 3).

The assignments of atomic contributions to the various valence band photoemission features are in generally good agreement with the $l$ projected density of state calculations obtained using the FEFF8-code performed on the system, whose results are shown in Fig. 1b. The valence band photoemission features displayed in Fig. 2, corresponds to features in the model calculations indicated by the position of vertical lines $1-5$, plotted relative to the Fermi energy as estimated by FEFF8, in Fig. 1b. The energy positions of structures 1-4 found in the photoelectron spectra can be 
easily assigned to prominent features in the $l$ and $d$ projected density of states plot, which in turn leads to a straightforward verification of the results obtained by photoelectron spectroscopy.

The only major discrepancy is the energy position of the barium core levels (the 5th line in Fig. 1b), which can be explained by the fact that this density of states is not related to a valence band feature but a shallow core. It is thus subject to stronger relaxation to lower energies due to the presence of a core hole in the calculations. The core-shell separation is treated on a different theoretical level by the FEFF8 code.

\section{Segregation}

Although no magnetically "dead" surface layer was indicated in prior studies of this system [6], some surface segregation of some of the constituents of these nanocrystallites is indicated. This is abundantly clear from the changes in the density of states closest to the Fermi level, as seen in Fig. 4. Extensive annealing (at $685 \mathrm{~K}$ for $10 \mathrm{~h}$ in vacuo) of the sample leads to enhancement of the feature at 1.8 $\mathrm{eV}$ binding energy, indicating that barium and cobalt are enriched near the surface region, while iron is depleted at the surface compared to the bulk $\mathrm{BaFe}_{12-2 x} \mathrm{Co}_{x} \mathrm{Ti}_{x} \mathrm{O}_{19}$. This is evident from the shift in the spectral peaks near $60 \mathrm{eV}$ from the broad feature at $61 \mathrm{eV}$ (unoxidized Co $3 p$ is nominally at $58.9 \mathrm{eV}$ binding energy, while unoxidized $\mathrm{Ti} 3 \mathrm{~s}$ is nominally at $58.7 \mathrm{eV}$ ) to features at 58 and $56 \mathrm{eV}$ binding energy (unoxidized $\mathrm{Fe} 3 \mathrm{p}$ is nominally at $52.7 \mathrm{eV}$ binding energy). Such segregation, following extensive annealing, does not require a magnetically dead layer at the surface of the crystallites as ferromagnetic Co doped titanium oxide is known.

While there has been some speculation concerning a dead layer in cobalt and titanium doped barium ferrites, from magnetic modeling [24], such a layer would be less than 1 $\mathrm{nm}$ to be consistent with the photoemission results presented here. The limited mean free path of the photoelectrons indicates that the segregation layer is quite thin, even after extensive annealing, consistent with the very short argon ion sputtering time needed to remove the segregation layer. Even if the segregation leads to a material that is nominally paramagnetic, solutions to the Landau-Ginzburg equation [25] indicate that a layer so thin $(<1 \mathrm{~nm})$ would have an induced magnetization by proximity.

\section{Summary}

We find that barium and iron contribute the greatest density of states near the Fermi level in nanocrystalline barium ferrite $\mathrm{BaFe}_{12-2 x} \mathrm{Co}_{x} \mathrm{Ti}_{x} \mathrm{O}_{19}$ particles. The strong hybridization of the barium and iron, mediated by oxygen, is expected, but the lack of uniform placement of cobalt and titanium needs further study. The segregation process in this system, with annealing, is under investigation, but may well provide insight into the alkaline earth titinate to $\mathrm{Fe}_{3} \mathrm{O}_{4}$ interfaces [26].

\section{Acknowledgements}

The support of the Center for Advanced Microstructures and Devices (CAMD), the Louisiana Board of Regents, the NSF "QSPINS" MRSEC (DMR 0213808), and the W.M. Keck Foundation Center for Mesospin and Quantum Information Systems are gratefully acknowledged. Also gratefully acknowledged is financial support by the DFG within the SPP1104 (contract no. Mo940/1).

\section{References}

[1] J. Park, K.J. An, Y.S. Hwang, J.G. Park, H.J. Noh, J.Y. Kim, J.H. Park, N.M. Hwang and T. Hyeon, Nat. Materials 3 (2004), p. 891.

E. Kang, J. Park, Y. Hwang, M. Kang, J.G. Park and T. Hyeon, J. Phys. Chem., B 108 (2004), p. 13932.

[2] P. Görnert, E. Sinn and M. Rösler, Key Eng. Mater. 58 (1991), p. 129.

[3] R. Müller, J. Magn. Magn. Mater. 120 (1993) 61; P. Görnert, H. Pfeiffer, E. Sinn, R. Müller, W. Schüppel, M. Rösler, X. Batlle, M. Garcia del Muro, J. Tejada and S. Gali, IEEE Trans. Magnetics 30 (1994) 714.

[4] J. Tang, Kai-Ying Wang and Weilie Zhou, J. Appl. Phys. 89 (2001), p. 7690.

[5] K. Hanea, Can. J. Phys. 65 (1987), p. 1233.

[6] R. Müller, R. Hiergeist, W. Gawalek and A. Hoell, Magnetohydrodynamics 39 (2003), p. 47.

[7] P.A. Dowben, Surf. Sci. Rep. 40 (2000), p. 151.

[8] D.N. McIlroy, S.-H. Jiandi Zhang, S.H. Liou and P.A. Dowben, Phys. Lett., A 207 (1995), p. 367.

[9] Jiandi Zhang, D.N. McIlroy, P.A. Dowben, S.-H. Liou, S.F. Sabiryanov and S.S. Jaswal, Solid State Commun. 97 (1996), p. 39.

[10] D.N. Mcllroy, C. Waldfried, J. Zhang, J.-W. Choi, F. Foong, S.-H. Liou and P.A. Dowben, Phys. Rev. B 54 (1996), p. 17438.

[11] Carlo Waldfried, D.N. McIlroy, S.-H. Liou, R. Sabiryanov, S.S. Jaswal and P.A. Dowben, J. Phys. Cond. Matt. 9 (1997), p. 1031.

[12] T. Saitoh, A.E. Bocquet, T. Mizokawa, H. Namatame, A. Fujimori, M. Abbate, Y. Takeda and M. Takano, Phys. Rev. B 51 (1995), p. 13942.

[13] J.-H. Park, C.T. Chen, S.-W. Cheong, W. Bao, G. Meigs, V. Chkararian and Y.U. Idezerda, Phys. Rev., Lett. 76 (1996), p. 4215.

[14] D. Mcilroy, J. Zhang, S.H. Liou and P.A. Dowben, Phys. Lett., A 207 (1995), p. 367.

[15] C.N. Borca, Bo Xu, Takashi Komesu, Hae-Kyung Jeong, M.T. Liu, S.-H. Liou, S. Stadler, Y. Idzerda and P.A. Dowben, Europhys. Lett. 56 (2001), p. 722.

[16] C. Waldfried, D.N. McIlroy and P.A. Dowben, J. Phys: Condens. Matter 9 (1997), p. 10615.

[17] A.L. Ankudinov, B. Ravel, J.J. Rehr and S.D. Conradson, Phys. Rev., B 58 (1998), p. 7565.

[18] H. Modrow, S. Bucher, J.J. Rehr and A. Ankudinov, Phys. Rev., B 67 (2003), p. 035123.

[19] B. Gilbert, B.H. Frazer, A. Belz, P.G. Conrad, K.H. Nealson, D. Haskel, J.C. Lang and G. de Stasi, J. Phys. Chem. A 107 (2003), p. 2839.

[20] K.H. Hallmeier, L. Uhlig and R.J. Szargan, J. Electron Spectrosc. Relat. Phenom. 122 (2002), p. 91.

[21] M. Lemonnier, O. Collet, C. Depautex, J.M. Esteva and D. Raoux, Nucl. Instr. Meth. A 152 (1978), p. 109.

[22] P.A. Dowben and D. LaGraffe, Physics Lett. A144 (1990), p. 193.

[23] Y. Sakisaka, T.N. Rhodin and P.A. Dowben, Solid State Comm. 49 (1984), p. 563.

[24] S. Kurisu, T. Ido and H. Yokoyama, IEEE Trans. Magn. MAG-23 (1987), p. 3137.

[25] A. Miller and P.A. Dowben, J. Phys. Condensed Matter 5 (1993), p. 5459.

[26] A. Lussier, Y.U. Idzerda, S. Stadler, S.B. Ogale, S.R. Shinde and V. Venkatesan, J. Vac. Sci. Technol., B 20 (2002), p. 1609. 